\title{
ALGUNOS ASPECTOS TEÓRICO-CONCEPTUALES Y SITUACIONALES QUE SOPORTAN LA INTEGRACIÓN CAN-MERCOSUR PARA LA ECONOMÍA COLOMBIANA
}

\author{
MARCO ANTONIO BURGOS FLÓREZ \\ Docente. \\ Universidad de Nariño
}

\section{RESUMEN}

El proceso de integración económica Can-Mercosur desarrolla empáticas formas de productividad en el desarrollo del sector agrícola de Colombia, a través del presente artículo se considerará de manera teórico-conceptual cuales han sido los movimientos benéficos y las desventajas de este proceso enmarcado en los niveles tales como: zona de libre comercio (ZLC), unión aduanera (UA), mercado común (MC), unión económica (UE) y por ultimo integración económica total (IET). Niveles imprescindibles en la formulación de los aspectos estáticos y dinámicos que determinan la actividad de consumidores como productores. Partiendo además de un análisis posible en una unificación que se visiona desde el Regionalismo y su carácter democrático siendo la "camisa de fuerza" para la economía nacional, a partir de ella se discurre cuáles son las causas endógenas y exógenas que generan grandes dificultades que justifican sus negaciones y sus efímeros logros para la Integración Regional, además de la necesidad de apelar a las metodologías "asimetrías" como formas de liderar que enmarcan la posibilidad de un progreso integral del territorio en elementos de ligaduras sociales, económicas, culturales, históricas, geográficas, que son la base del mercado regional para la economía colombiana.

Palabras clave: Can-Mercosur, Desarrollo, regionalismo, asimetrías, integración.

\section{ABSTRACT}

The Can-Mercosur economic integration process develops empathic forms of productivity in the development of the Colombian agricultural sector, through this article will be considered in a theoretical-conceptual way what have been the beneficial movements and the disadvantages of this process framed in the levels Such as: free trade area (FTA), customs union (UA), common market (MC), economic union (EU) and last total economic integration. Essential levels in the formulation of the static and dynamic aspects that determine the activity of consumers as producers. Starting from a possible analysis in a unification that is seen from the Regionalism and its democratic character being the "straitjacket" for the national economy, it is based on it which are 
the endogenous and exogenous causes that generate great difficulties that justify Its negations and its ephemeral achievements for Regional Integration, as well as the need to appeal to the methodologies "asymmetries" as forms of leadership that frame the possibility of an integral progress of the territory in elements of social, economic, cultural, historical, geographical ties, Which are the basis of the regional market for the Colombian economy.

Key words: Can-Mercosur, Development, regionalism, asymmetries, integration.

Hoy después del paro agropecuario, en donde se debate el volver al proteccionismo para resguardar la economía colombiana, se hace una pequeña reflexión si dicho proceso de integración comercial con el Mercosur debe o no continuar. Para ello se enmarcara este presente escrito en soportar de manera teórico conceptual los beneficios del proceso y un pequeño análisis de la importancia del mercado regional para la economía colombiana.

Cabe destacar que la negociación entre los dos bloques comerciales suramericanos Comunidad Andina de Naciones CAN y Mercado Común del Sur Mercosur, presentaron un nuevo escenario para el desarrollo de la política económica internacional colombiana, desde que comenzaron sus negociaciones en 1995 , y más aún en la concreción de la denominada Integración Suramericana, que como primer paso tiene en el año 2004 un Acuerdo de Complementación Económica 59 para formar una denominada Zona de Libre Comercio Suramericana (ZLCS) con desgravación arancelaria a 18 años y posteriormente una Comunidad Suramericana de Naciones (CSN) (CAN, Acuerdo de Complementación Económica 59 del 2004).

Integración a niveles suramericanos, que para muchos países no tendría el impacto que tiene para la economía colombiana, quien siendo miembro fundador de la CAN y el de mayor peso económico, tiene su mayor socio comercial externo a la región suramericana y su modelo de desarrollo se soporta sobre una fuerte política de liberación comercial en contraste con la política de los países del Mercosur con un marcado regionalismo comercial; lo cual establecen un reto a su política económica internacional de ampliar el mercado a sus productos en la región y fuera de ella.

Las relaciones comerciales internacionales son el resultado de ámbitos tanto naturales como artificiales, que han hecho que las economías de diferentes países logren desarrollar actividades comerciales de manera fluida sin inconvenientes de los aspectos fronterizos sobre ellas. En el ámbito natural, son el surgimiento de relaciones comerciales espontáneas que dados los beneficios del comercio internacional, han marcado el rumbo de dichos procesos. En el ámbito artificial se establecen las relaciones fruto de la acción decidida del Estado de favorecer las relaciones comerciales con determinado o determinados países, profundizando las relaciones naturales comerciales o generando nuevas relaciones. Para la humanidad el Estado es posterior al desarrollo de la sociedad y el comercio responde a la necesidad del hombre de satisfacer de mejor manera sus carencias a través del intercambio comercial, el cual sobrepasa en muchos casos los ámbitos fronterizos establecidos por el Estado.

Así, a lo largo de la historia de la participación del Estado en la economía y específicamente en torno al ámbito internacional, la mayoría de países han 
oscilado entre el liberalismo y el proteccionismo de sus economías, donde las decisiones políticas y económicas se entrelazan para justificar dichos procesos. Es así, como después de la segunda guerra mundial, muchos países toman la difícil decisión de integrarse comercialmente, muchos se inclinan a participar activamente en las liberaciones comerciales multilaterales (multilateralismo), otros apuntan a participar en bloques comerciales (regionalismo), algunos más juegan en ambos bandos y otros por el contrario negocian con algunos países que consideran beneficiosos para su actividad económica (bilateralismo). Todas estas, diferentes formas de integración económica, que mueven al mundo y hacen el mercado capaz de generar la escala productiva de la innovación y desarrollo que vive la humanidad.

Entendiendo que la Integración económica es un proceso, este se encuentra acompañado de medidas dirigidas a abolir la discriminación entre unidades económicas pertenecientes a diferentes naciones, que vista como una situación de los negocios, la integración viene a caracterizarse por la ausencia de varias formas de discriminación entre economías nacionales (Balassa, 1980:1) ${ }^{1}$. Así, los procesos de integración puede pasar por diferentes niveles como: zona de libre comercio (ZLC), unión aduanera (UA), mercado común (MC), unión económica (UE) y por ultimo integración económica total (IET). No cabe duda que la UA implica una etapa importantísima del desarrollo de todo proceso de integración económica, dado que la Zona de Libre Comercio (en adelante ZLC), es una etapa que está inmersa en la integración comercial a la cual se es fácil acceder a partir de la disminución

1. BALASSA, Bela (1980). Teoría de la integración. México: Uteha S.A, 1980, p. 1. de las discriminaciones comerciales, lo que no va más allá que a un tratado que libere el comercio sin necesidad de perder autonomía en torno al comercio con otros países, siendo esta etapa a la que todas las economías del mundo han transitado o están transitando.

Por el contrario, la UA como su nombre lo dice implica una homogenización en el trato comercial con terceros países, lo que implica una pérdida de la soberanía comercial del país, sobre todo en la discrecionalidad de la política comercial al no poder comerciar libremente y generar tratos más acordes a sus intereses particulares. No obstante, existiendo las condiciones necesarias para desarrollar una UA, sus beneficios económicos serán mayores a las ZLC, las cuales presentan enormes costos no solo económicos.

Las ventajas de la integración comercial están más tendientes a los aspectos estáticos de la integración como el incremento del consumo, la variedad de bienes y servicios, la disponibilidad de materias primas, insumos y bienes de capital. Pero también a los aspectos dinámicos de la misma como las economías de escala, la transferencia tecnológica y el aprendizaje; elementos que van más allá de una integración comercial y son el resultado de una cooperación económica entre países hermanos.

Muchos acuerdos comerciales no pasan de llegar a constituirse en ZLC, es más, solo se crean bajo ese objetivo, ellos visualizan que la UA no es un aspecto importante para su desarrollo, por el contrario limita su visión de mercados mucho más amplios para su comercio y que esa maniobrabilidad en el ámbito comercial con terceros es un instrumento discrecional importante en sus relaciones comerciales mundiales. Aquí ya se comienza a ver las dificultades que presenta para un país la integración económica en una UA. El avance o no de 
una ZLC a una UA determina un costo beneficio para ciertos bloques comerciales, dado que la UA es un área de libre comercio más un arancel externo común (AEC), lo cual sin lugar a dudas está enmarcado en las concepciones del desarrollo de los países involucrados y de las posibilidades que estos tienen en la producción, el consumo y los términos de intercambio en un corto y largo plazo.

Es así como, para dos países que han tomado la decisión de pertenecer a dos bloques comerciales, las negociaciones entre bloques reflejan una gran oportunidad para ellos y la región de posibilitar incrementar mucho más el mercado, elemento necesario para ampliar la base productiva con valor agregado, no sin cambios en ámbitos económicos, políticos y sociales.

Hoy en día ya no se cuestiona si un país quiere o no estar en la globalización, el hecho de tener fronteras lo obliga a mirar el mundo y darle a los Estados el papel de insertarse de la mejor manera en ella. No obstante, los consumidores y productores ven las ventajas y desventajas que dicho proceso tiene para sus bolsillos y sus arcas, intereses que motivan a la actuación del Estado y generan tensiones sobre su papel económico, dadas las contradicciones que puede existir en los intereses. Papel que se complica más al conjugarse intereses de estos actores con actores externos, que aumentan la presión y pueden llegar a hacer deslegitimar su papel de actor nacional e internacional.

Quizá la búsqueda por así llamarlo de un óptimo en su política económica internacional que beneficie tanto a consumidores, productores y actores internacionales, es el ideal de todo Estado en el proceso de apertura económica. Pero no cabe duda, que estas peticiones se soporten en intereses de corto plazo; las cuales pueden estar en contraposición a intereses nacionales soportados en ámbitos constitucionales que obligan a los Estados a buscar un mayor desarrollo y cerrar brechas relativas en las condiciones de vida de su población. En este sentido estaríamos hablando de un nivel que no solo apremia el corto plazo sino el largo plazo, que bien podríamos llamar intereses nacionales en los procesos de apertura.

Así planteado, el Estado tiene y seguirá teniendo el importante papel de conducir la economía de manera armónica entre la eficiencia y equidad de la economía, lo cual solo se lograría a partir de apuntar a las ventajas del libre comercio pero haciendo que sus ganancias posibiliten en primer lugar estímulo a la inversión en beneficio de empresarios; así como recursos al Estado que posibiliten resarcir los daños ocasionados por posibles desplazamientos de la mano de obra como pueden ser salarios bajos, subempleo, vacancia temporal y desempleo; lo cual conduciría a sostener el proceso de liberalización. De igual manera, le corresponderá al Estado desarrollar estudios prospectivos de competitividad de la economía bajo escenarios de liberalización, que le permitan consolidar ventajas competitivas, las cuales dependen de la capacidad transformadora de su población y son fruto del cambio cultural y educacional.

La evidencia histórica ha demostrado que las integraciones económicas de países se han hecho no sin sacrificios y la mayoría de ellas bajo la perdida de ámbitos de soberanía. Muchas de ellas no han pasado de ser integraciones comerciales $\mathrm{y}$ han evidenciado las desigualdades de distintos tipos que imposibilitan profundizar la integración. Las dificultades de la economía global para avanzar en una mayor integración, son las mismas que se pueden tener a niveles regionales de integración más profunda, es así como 
"la democracia, soberanía nacional e integración económica.... son mutuamente incompatibles: podemos combinar cualesquiera dos de las tres, pero nunca tener las tres simultáneamente y en su esplendor"2. Tal es el caso que si planteamos como país una integración regional más profunda, tendremos que ceder nuestras políticas democráticas a un ámbito de federalismo regional, que en muchas ocasiones implica no tener la libertad de su aplicación, sino el juego del consenso regional para ello. Así, los compromisos adquiridos juegan como una camisa de fuerza para las economías nacionales, lo que plantea enormes dificultades a la integración regional profunda.

Ello también establece que estos tres elementos son ámbitos difíciles de mantener para un país, más aun para aquellos países que se unen en condiciones económicas de riesgo, en donde las crisis mundiales demanda mayores sacrificios de sus comunidades, las cuales laceran los niveles mínimos de aguante de estos tres ámbitos y responden con proteccionismo, política expansiva o ajuste. De ahí que el problema de los países por así decirlo "débiles" socaba la confianza mundial de los países "fuertes" que están asociados a él y que evidencian su poder como líderes del grupo, así mismo la crisis de estos grandes de plano son la hecatombe de los pequeños. Todo ello evidencia una fuerte interdependencia en los ámbitos no solo económicos, sino sociales, políticos y medioambientales; la cual se amplía en la medida de la mayor integración.

Cabe resaltar que se hace necesario un mayor análisis de la necesidad de la

2. RODRIK, Dany (2007). "El indefectible trilema de la economía mundial", en: Globalización.org. Obtenida el 15 de junio de 2010 de http://www.globalizacion. org/globalizacion/ RodrikGlbzTrilema.htm ampliación de las relaciones comerciales a toda América del sur por parte de las uniones aduaneras establecidas, a la importancia de las relaciones entre países de diferentes bloques, a la apuesta de combinar el comercio interregional, a la necesidad de no anteponer elementos políticos a los económicos cuando los argumentos deberían ser los resultados de estos últimos.

En cuanto al proteccionismo, no cabe duda que los países con una presencia industrial importante en la región como Argentina y Brasil, y en menor caso Colombia, han tenido un desarrollo gracias a políticas proteccionistas, pero estas están lejos de ser competitivas en relación con industrias de otros países también en desarrollo. El tener una gran industria como parte del producto interno bruto, no determina que se tenga un mejor desarrollo. "Un periodo de protección no crea un sector manufacturero competitivo si hay razones fundamentales por las que un país carece de ventajas comparativas en la producción de manufacturas. Los países pobres carecen de mano de obra cualificada, de empresarios, de ejecutivos competentes, y tienen problemas de organización social que dificultan el mantenimiento de una oferta fiable de todos los bienes, desde piezas de repuesto hasta electricidad. Esos problemas pueden no estar fuera del ámbito de la política económica, pero no pueden ser resueltos por la política comercial: una cuota de importación puede permitir la supervivencia de un sector manufacturero ineficiente, pero no hace directamente a dicho sector más eficiente. El argumento de la industria naciente es que, dada la protección temporal de aranceles o cuotas, las industrias manufactureras de los países menos desarrollados aprenderán a ser eficientes. En la práctica esto no es siempre, ni 
generalmente, verdad"3. Es aquí donde se vislumbra una adecuada opción en la mayor integración CAN-Mercosur, la ampliación de un mercado que posibilite el desarrollo de sectores de mayor valor agregado de la economía, sin mayores costos políticos como es el abrir la economía a la competencia internacional, fuerte en dichos sectores y subsidiada en otros generadores de mano de obra no calificada. Así mismo, la mayor competencia industrial del área regional, conlleva a dinamizar ciertos sectores de la economía todavía protegidos, sin mayores niveles de calidad. Visto esto, el Mercosur representa para la CAN y en sí para Colombia un mercado superior a su población, con una industria competitiva en algunos sectores y complementaria en otros, así como una agricultura en iguales condiciones, es decir una economía adecuada para una integración comercial de mutuo beneficio y comprometida con el desarrollo regional.

En un muy interesante aparte del análisis de Bela Balassa, denominado "efectos de la producción, en una Unión Latinoamericana", el autor plantea que existen restricciones a la especialización interregional, dadas por la inflexibilidad e inseguridad asociadas al comercio bilateral. Lo que ha conllevado a que muchos países tengan capacidad instalada excedente sobre todo en manufacturas, que se podría utilizar si se llegara a una integración regional que amplíe el mercado regional, esperando que la demanda de productos manufacturados sea creciente, es decir la integración vaya pari passu con el desarrollo económico ${ }^{4}$.

Como se ha planteado antes, es innegable que la integración regional tenga

3. KRUGMAN, Paúl y OBSTFELD, Maurice (2006). Economía Internacional: Teoría y política. Séptima edición. Madrid: Ed. Pearson Educación S.A., p. 265.

4. BALASSA, Bela, Op. Cit., 1980. grandes dificultades que evidencian sus fracasos o solo logros parciales del proceso. Estudios han mostrado que de los cientos de acuerdo de integración firmados en el mundo, muy pocos pueden considerarse exitosos o juzgarse satisfactorios. Causas endógenas y exógenas a los tratados de integración son los responsables, como: la excesiva rigidez del Tratado, la inestabilidad política de la región, la falta de una estrategia común de inserción internacional, la gran heterogeneidad económica y por decirlo así unos objetivos demasiado ambiciosos de los tratados ${ }^{5}$. En otro ámbito, se plantea que de las causas que afectan todo proceso de integración regional en sus fracasos o logros parciales están factores externos como: conflictos entre bloques económicos, la configuración de la tria$d a$, la compatibilidad entre regionalismo y multilateralismo, etc. También, existe el aspecto de la "deseabilidad" de la integración regional en sí, que es una cuestión muy importante ${ }^{6}$.

Así mismo, se habla de factores internos que apuntan a la existencia de la asimetría en los esquemas de integración. "En efecto, las asimetrías en las condiciones iniciales o en términos de poder de negociación en el grupo de países pueden dificultar u obstaculizar el proceso de negociación. Sin embargo, las asimetrías pueden también actuar como motores de la integración; por ejemplo, en la presencia de un país que lidere y dirija el proceso de integración de un grupo de países"7.

5. GRANATO, Leonardo (2006). "Aportes para la protección y defensa del inversor extranjero en el Mercosur". Obtenida el 10 de abril de 2011 de http:// www.eumednet/libros/2006b/lg/ index.htm

6. DE LOMBAERDE, Philipe (2002). Integración Asimétrica y Convergencia Económica en las Américas. Editor: Grupo de Investigación en Economía Internacional GREI. Universidad Nacional de Colombia,

Bogotá, p. 18.

7. Ibídem, p. 18 
De igual manera en torno a las asimetrías en los procesos de integración, cabe destacar que también hay asimetrías en los efectos de la integración regional: que incluyen los efectos estáticos (creación y desviación de comercio, efectos recíprocos sobre el comercio entre los radios de un sistema eje-radios, efectos sobre los flujos de inversión, etc.) y los efectos dinámicos (efectos de competencia, economías de escala, efectos sobre el crecimiento, etc.). Todos estos efectos pueden mostrar asimetrías en la medida de que afecten de manera asimétrica los países involucrados y son una función de las demás asimetrías que se podrían agrupar en: asimetrías estructurales, asimetrías en los compromisos adquiridos, asimetría en el proceso de toma de decisiones y en el diseño organizacional ${ }^{8}$.

Muchos tratados de integración han reconocido esas asimetrías y han incorporado en los mismos, una serie de elementos que posibilitan los menores efectos negativos de dichas asimetrías sobre las economías de los países. Elementos de gradualidad, selectividad y trato diferencial, han sido necesarios para generar ambientes de consenso sobre los procesos de integración. Llegándose hasta el nivel de establecer un denominado "menú a la carta" para la integración de los países, lo cual evita la renuencia de muchos países a la integración regional bajo el argumento de enormes efectos negativos para sus economías en dicho proceso.

El proceso de integración regional para las economías de los países en desarrollo, enmarca la posibilidad de un desarrollo armónico del territorio en elementos de vínculos sociales, económicos, culturales, históricos, geográficos, etc., lo cual plantea la posibilidad de

8. Ibídem, p. 23. una adecuada política de integración y cooperación que propenda por mejorar los niveles de vida de estos en sus bloques. Así mismo, se ha establecido que el desarrollo de los países de menor desarrollo en determinadas regiones es un elemento necesario para evitar que sus problemas repercutan en la calidad de vida de sus socios o vecinos con mejores niveles de vida.

Hoy en día, existe la necesidad de mirar de frente a la globalización, de posibilitar de la mejor manera incrementar los mercados para los países, de lograr una adecuada estrategia de integración, de complementar el proceso de apertura con mejoramiento de la estructura económica y social, de avanzar en procesos mucho más allá de los acuerdos comerciales, de reconocer que el proceso de integración regional es parte de una mayor liberación, pero con la flexibilidad, selectividad y gradualidad necesarias para su consenso en la sociedad.

En este último siglo, desde cuando se propone la negociación de una América Latina en libre comercio como una respuesta a la necesidad de un mayor mercado a tono con los procesos de sustitución de importaciones, el espíritu de la integración siempre ha estado ligado a los procesos de desarrollo y crecimiento regional. Procesos de liberación comercial ambiciosos liderados por instituciones a esfera mundial como el GATT (1947) hoy Organización Mundial del Comercio OMC (1995), y de carácter continental como la Asociación Latinoamericana de Libre Comercio Alalc (12 de febrero de 1960) y su sucesora la Asociación Latinoamericana de Integración Aladi (12 de agosto de 1980), no han tenido los resultados liberatorios como lo han tenido los procesos de integración regional CAN (origen 1969 y consolidación 1996) y Mercosur (origen 1991 y consolidación 1995), ello 
dadas las enormes complejidades por los diferentes intereses de los países y una marcada connotación geográfica del comercio. Cabe destacar que el carácter posterior de los bloques económicos CAN y Mercosur, es el resultado de una propuesta de ampliar los mercados nacionales a entornos regionales, en cierta medida como respuesta a la frustración de una integración Latinoamericana de mayor mercado. Es así, que en los dos procesos quedó plasmado dentro de sus objetivos, el avanzar en la ampliación de los mismos a una integración mayor no solo comercial sino económica, lo cual sin lugar a dudas sería el resultado de sus éxitos y de los acontecimientos mundiales y regionales.

No cabe duda, que la integración latinoamericana es un gran propósito, pero ello se queda en la voluntad de los Gobiernos y en la visión inmediatista del mismo. La historia ha demostrado las dificultades del primer proceso integrador latinoamericano: la Asociación Latinoamericana de Libre Comercio (ALALC), "En este caso, la situación de los incumplimientos resultó tan persistente y profunda que conllevó a la eliminación del esquema inicial de integración económica orientado a la formación de una zona de libre comercio y su transformación o retroceso a una zona de preferencias arancelarias, concentrando la atención en una liberación comercial más limitada, privilegiando el camino de la bilateralidad, lo que llevó a la reforma y suscripción de un nuevo Tratado de Montevideo de 1980"9.

Hoy en día, nos acercamos más a la integración Suramericana que a una

9. ARELLANO, Félix G. (2004) "Comunidad Andina: de la zona de Libre Comercio a la Unión Aduanera. Los nuevos temas", en: Aldea Global, Año $8 \mathrm{~N}^{\circ} 16$, pp. 5-15. Obtenida el 20 de octubre de 2010 de http:// www.saber.ula.ve/bitstream/123456789/18166/1/ articulo16-1.pdf
Latinoamericana y menos Americana, esta última denominada en su propuesta Área de Libre Comercio de las Américas, ALCA, la cual encontró enormes críticas a su realización por parte de los países suramericanos en especial del Mercosur dado el interés Norteamericano en dicho proceso, lo cual ha planteado un giro en la integración de este bloque, hacia una aceleración de la propuesta de ampliación del mismo a sus vecinos del sur, sin hacerlo extensivo a toda Latinoamérica, dados los acuerdos vigentes de integración entre Norte y Centro América.

Es así como se llega a la Integración Can-Mercosur, que tiene como punto máximo el acuerdo de complementación económica ACE No. 59, suscrito entre los bloques en el año 2004 y que según sus objetivos va más allá de la integración comercial:

- Alcanzar el desarrollo armónico en la región, tomando en consideración las asimetrías derivadas de los diferentes niveles de desarrollo económico de las Partes Signatarias;

- Promover el desarrollo y la utilización de la infraestructura física, con especial énfasis en el establecimiento de corredores de integración que permita la disminución de costos y la generación de ventajas competitivas en el comercio regional recíproco y con terceros países fuera de la región;

- Promover e impulsar las inversiones entre los agentes económicos de las Partes Signatarias;

- Promover la complementación y cooperación económica, energética, científica y tecnológica;

- Promover consultas, cuando corresponda, en las negociaciones comerciales que se efectúen con terceros 
países y agrupaciones de países extra regionales ${ }^{10}$.

En torno a la importancia del mercado regional, la integración Can-Mercosur, es de gran importancia para la política económica internacional colombiana, dada la conformación de un Mega bloque comercial fruto de un novedoso proceso de integración de bloques comerciales, donde sus socios comerciales harían parte y en el que estarían nuevos competidores directos de sus productos, en especial de sus productos con valor agregado. Así mismo, por el tamaño del mercado, el nuevo bloque es un gran atractivo para el sector externo colombiano, más aún cuando el país necesita un giro en su política comercial externa dada la firma del TLC con los Estados Unidos de Norteamérica su mayor socio comercial, con lo cual se consolidan sus preferencias arancelarias y se establece un gran atractivo para la inversión extranjera en el país. Cabe destacar que dicho TLC fue propuesto por Colombia y que tuvo un largo debate en el Congreso Norteamericano para su ratificación.

De igual manera la coyuntura política regional apunta a que los principales socios comerciales de Colombia en la región, se consoliden en un sub bloque económico por medio de tratados comerciales y de cooperación, que dejen por fuera de dichos beneficios al país y le generen pérdidas en el mercado regional, lo cual se comienza a ver desde

10. Comunidad Andina de Naciones, CAN (2004). Acuerdo de Complementación Económica No. 59, suscrito entre los gobiernos de la República Argentina, de la República Federativa del Brasil, de la República del Paraguay y de la República Oriental del Uruguay, Estados partes del Mercosur y los gobiernos de la República de Colombia, de la República del Ecuador y de la República Bolivariana de Venezuela, países miembros de la Comunidad Andina. Secretaría General. Documentos informativos SG/di 671, noviembre 2 de 2004. Obtenida el 20 de octubre de 2010 de http://intranet.comunidadandina.org/ Documentos/D Informativos/SGdi671.pdf la salida en el año 2005 de Venezuela de la CAN y su petición de incorporación al Mercosur como país miembro; así mismo el mayor nivel de comercio internacional de Ecuador y Bolivia con el bloque del sur. No cabe duda, que la crisis que presenta la CAN es una condición para que Colombia haya planteado seguir con su política de apertura comercial y la integración con el Mercosur tenga espacio en su política de regionalismo abierto.

El acuerdo Can-Mercosur como se ha establecido anteriormente, es beneficioso para la economía colombiana, dado el tamaño del bloque, el potencial de demanda de productos manufacturados, la posición estratégica del país y sin lugar a dudas, el trato preferencial dado a Colombia en el Acuerdo de Complementación Económica propuesto.

La baja relación comercial de Colombia con el Mercosur ${ }^{11}$, antes de constituirse en un elemento de determinar la menor importancia de dicha integración, es por el contrario una posibilidad para la ampliación del mismo. En el caso de Colombia que tiene mucho más gasto en las importaciones norteamericanas que suramericanas, la integración suramericana no tendrá mayores trastornos si no se llega a una unión arancelaria, y solo se establece un área de libre comercio, ya que establecidos los TLC con los Estados Unidos, el comercio abierto no generará prohibiciones que traigan desviaciones de comercio sino que posibilitarán una competencia para los bienes regionales y los provenientes del extranjero que reducirán los precios y beneficiaran a

11. "Es así como entre el año 1994 y el 2005, en promedio Colombia exportó al Mercado Común del Sur solo el $1.6 \%$ del total de sus exportaciones, mientras que a Estados Unidos envió el 40\%”. SIERRA, Lya Paola (2008). Impacto del acuerdo Can-Mercosur en las exportaciones del departamento del Valle del Cauca, Colombia. Perspectivas internacionales. Cali, Colombia, vol. 4 no 1, enero-junio. Issn 1900-4257. Pág. 110. 
los consumidores y productores que se abastezcan de materas primas e insumos de origen regional.

No cabe duda que la entrada de Colombia al Mercosur, al igual que todos los países de la CAN, han sugerido la existencia de dos problemas claros: el Arancel Externo Común AEC y el proceso de liberalización comercial. A los cuales se ha planteado como solución un trato diferencial para los países de la CAN que tienen TLC con países extra región, así como una liberación gradual diferencial, planteándose, que la voluntad integracionista debe estar por encima de estas problemáticas, de ahí la necesidad de establecer una adecuada exigencia de contenido nacional a las mercancías comerciadas, evitando que las negociaciones con terceros países hagan tránsito de mercancías extra región.

Desde el comienzo de las negociaciones del TLC con Estados Unidos el argumento de los beneficios del mismo fueron: el gran mercado para las exportaciones colombianas, la ayuda económica, y en especial la inversión extranjera; elementos que sin lugar a dudas se plantean son posibles con la integración al Mercosur un nuevo actor dentro de esos beneficios, los cuales pueden consolidarse aún más al pasar de una ZLC como es el TLC a un mercado común, ámbito solo contemplado en la integración al sur. Si el modelo de apertura comercial colombiano es liberalismo a ultranza, la integración regional es un elemento importante en su esquema y el mayor resultado de cada acuerdo dependerá de una adecuada política de cumplimiento de los mismos.

Si se tiene en cuenta que Colombia presenta sus cinco principales productos de exportación para el año 2007 en: Petróleo (19\%), carbón (11.5\%), café (7.0\%), flores (4.3\%) y ferro aleaciones (3.5\%); representando estos el $45.3 \%$ de las exportaciones totales para dicho año ${ }^{12}$, y que estos en su gran mayoría se exportan fuera de Suramérica, se deduce que el impacto negativo de la integración, no podría ser de grandes proporciones al sector exportador colombiano por pérdida de mercados en la CAN. Aquí se puede deducir que el gran impacto lo tendría sin lugar a dudas el sector industrial colombiano, el cual perdería comercio con la CAN y sería sustituido por producción del Mercosur. No obstante, las potencialidades dadas por su vocación fabril y salarios más competitivos con respecto a los dos colosos del sur, hacen prever que en los nuevos ámbitos competitivos mundiales el aspecto laboral será fundamental a la hora de la inversión de los grandes productores.

Las ventajas comparativas de la economía colombiana están inclinadas a la producción agrícola de ciertos productos como los frutales, las hortalizas, los tubérculos, el algodón, el tabaco, la ganadería, los lácteos, las especies forestales, cacao, palma y caña. No sobre aquellos productos como el arroz, el maíz, la cebada y la soya; productos que generan poco empleo a diferencia de los primeros grandes generadores de empleo ${ }^{13}$.

12. Este es un indicador de concentración de las exportaciones, el cual indica que Colombia para el año 2007 con $45.3 \%$ tiene el puesto 8 entre 17 de los países de América Latina y del Caribe, muy por debajo del mayor que es $88.8 \%$ de Venezuela y encima del $30,5 \%$ de Argentina y $19.1 \%$ de Brasil, los menores. DURÁN, Lima José E. y ÁLVAREZ, Mariano (2008). Indicadores de comercio exterior y política comercial: mediciones de posición y dinamismo comercial. Comisión Económica para América Latina y el Caribe (Cepal). Naciones Unidas, Santiago de Chile.

13. REINA, Mauricio (2005). Escenarios de Colombia frente al ALCA. Las negociaciones comerciales de Colombia; del ALCA al TLC con los Estados Unidos. Juan Carlos Ramírez, editor. Cepal. Serie Estudios y perspectivas. Bogotá, Pág., 17. Obtenida el 16 de agosto del 2011 de http://www.eclac.cl/colombia/ noticias/documentosdetrabajo/0/20860/TLC_Col_ Usa_G-ES.pdf 
En torno a las negociaciones con Mercosur desde antes del ACE 59, indicadores de similitud de exportaciones planteaban que estas eran más competitivas que complementarias en el caso Brasilero, por encima de Estados Unidos, lo que llevó a que empresarios colombianos plantearan serias reservas en torno a la integración Can-Mercosur. Tal es el caso de los productos como joyería, manufacturas de cacao, chocolate y dulces, manufactura de productos alimenticios no clasificados y calzado ${ }^{14}$. Pero a pesar de tener desviaciones del comercio hacia los grandes países del sur, el marginarse del gran bloque suramericano sería aún peor.

Con respecto a las situaciones de defensa comercial de Colombia en la integración comercial con el Mercosur, se puede establecer que estas dan una gran posibilidad al país de actuación con mecanismos de defensa comercial como Salvaguardias Comerciales para productos específicos, Régimen para Productos Agropecuarios y Mecanismos para corregir la competencia desleal como Dumping y Subsidios. Cabe aclarar que los países acuerdan no aplicar al comercio recíproco industrial, subvenciones que resulten contrarias a lo dispuesto en la OMC, así como no aplicar al comercio recíproco agrícola, toda forma de subvenciones a la exportación ${ }^{15}$. "Se puede señalar que los Países Miembros de la Comunidad Andina incorporaron en sus acuerdos con los países del Mercosur y Chile mecanismos para atender problemas originados por el incremento de importaciones y optaron por recurrir a la norma multilateral para resolver las prácticas desleales de comercio como el

14. Ibídem.

15. CAN (2010). Acuerdo de Complementación Económica suscrito entre los Estados partes del Mercosur y los países miembros de la CAN. ACE $N^{\circ} 59$. Título VII. Aplicación y utilización de subvenciones. dumping y las subvenciones"16. Se espera que la Comisión Administradora creada para la administración y evaluación del presente Acuerdo, vele por el cumplimiento de las disposiciones del mismo ${ }^{17}$.

Es de esperarse que el comercio CanMercosur posibilite un crecimiento del comercio de Colombia con el Mercosur, no obstante, se puede hacer claridad de que para que el comercio se dinamice, se hacen necesarios "un conjunto de acciones o políticas que pueden impulsar el mejor aprovechamiento de los Acuerdos, tales como: promover la diversificación de las exportaciones; mejorar el acceso al crédito; impulsar la inserción externa de las Mipymes; reducir los costos de transporte; y mejorar la infraestructura"18. Elementos que se plantean claramente en el ACE 59.

Eso es sin duda alguna una gran potencialidad de las negociaciones Can-Mercosur, avanzar más allá de lo comercial y plasmarlo en el ACE 59, que como apunta la Aladi en el análisis descriptivo de dicho acuerdo, "su texto incorpora disposiciones sobre materias complementarias y acciones de desarrollo, complementación y cooperación en otros sectores económicos de interés mutuo y prevé que las medidas de liberación comercial irán acompañadas, de las siguientes actividades conjuntas y coordinadas:

- Establecimiento de un marco jurídico e institucional de cooperación económica y física para la libre

16. ALADI (2004). Convergencia comercial de los países de América del Sur hacia la Comunidad Sudamericana de Naciones. Mecanismos de Defensa Comercial.

17. CAN (2010). Acuerdo de Complementación Económica suscrito entre los Estados partes del Mercosur y los países miembros de la CAN. ACE No 59 . Título XXIII. Administración y evaluación del acuerdo.

18. ALADI (2010). Secretaría General. Evolución del comercio negociado y aprovechamiento de las preferencias arancelarias. Estudio 199. 22 de diciembre del 2010. 
circulación de bienes y servicios y la plena utilización de los factores productivos;

- Promoción de inversiones recíprocas;

- Medidas dirigidas a impulsar la complementación y cooperación económica, energética, científica y tecnológica, y a promover el desarrollo de la infraestructura física en especial aquellas que permitan la disminución de los costos operativos; $y$,

- Entendimientos para avanzar hacia la coordinación de posiciones en las negociaciones comerciales que se realicen con terceros países o con agrupaciones de países de fuera de la región" ${ }^{2}$.

Algunos análisis de la Aladi han demostrado, que los acuerdos no han posibilitado una mayor utilización de las preferencias arancelarias establecidas en ellos, y que entre más grande es la economía de un país, hay más utilización de las preferencias. Es así como los países grandes, tales como Argentina, con una utilización de las preferencias del 26,9\%, Brasil con 36\% y México con el 21,3\%; registran una mayor utilización. En un segundo nivel se encuentran Chile con 12,5\%, Colombia con $14,9 \%$ y Perú con 12,3\%; países con promedios similares al promedio general del 12,2\%. Los demás países latinoamericanos pertenecientes a la ALADI, presentan promedios inferiores al 6\%, constituyendo el tercer grupo.

19. ALADI (2005). Asociación Latinoamericana de Integración. Análisis Descriptivo del Acuerdo de Complementación Económica $\mathrm{N}^{\circ} 59$ Suscrito entre Argentina, Brasil, Paraguay y Uruguay Estados partes del Mercosur y Colombia, Ecuador y Venezuela países miembros de la Comunidad Andina. Secretaría General. SEC/di 1891. 3 de febrero de 2005.
Para el caso colombiano, se determina que de ese $85,1 \%$ no utilizado de las preferencias de los acuerdos, un 56,8\% corresponde a sin oferta exportable y un $24,5 \%$ corresponde a importaciones desde terceros mercados ${ }^{20}$.

En un análisis de cómo se han utilizado las preferencias de los acuerdos por parte de Colombia, se establece que para el país el ACE 59 (integración Can-Mercosur) es poco explotado. "Analizando el grado de utilización que realiza Colombia de las preferencias recibidas se observan básicamente tres situaciones. Por un lado, se registra un buen nivel de utilización con México $(22 \%)$ y con los países de la CAN que son limítrofes: Venezuela $(40,4 \%)$, Ecuador $(35,4 \%)$ y Perú $(22,1 \%)$. En una situación intermedia se encuentran las preferencias recibidas de parte de Bolivia $(13,6 \%)$, Cuba $(11,9 \%)$ y Chile $(9,3 \%)$ con una utilización moderadamente baja. En el otro extremo, las relaciones con los países del Mercosur registran un nivel muy bajo de utilización, en todos los casos inferior al 5\%"21. En este mismo análisis, se establece para el año 2010, que hay una estrecha relación con el aprovechamiento de los acuerdos y su antigüedad, por ello los acuerdos con los países no Mercosur son más antiguos y que el acuerdo con el Mercosur es relativamente reciente, por lo cual se espera que con el tiempo este vaya dando mejores resultados comerciales ${ }^{22}$.

\footnotetext{
20. ALADI (2010). Informe del secretario general Aladi sobre la evolución del proceso de integración regional durante 2008-2009. 4 de agosto de 2010.

21. Ibídem.

22. Ibídem.
} 
En torno a la lenta evolución del tratado comercial y su impacto en el comercio colombiano, el vicepresidente de Colombia del Gobierno Santos, Angelino Garzón, manifestaba en la XLI Cumbre de jefes de Estado del bloque, que la asociación por vía comercial ha tenido un proceso más lento de lo que se esperaba, y planteó una revisión con la que los beneficios del comercio aumenten para todos. Así como destacó que Colombia acudió a la cumbre con el fin de seguir profundizando su participación en el Mercosur, haciendo claridad de que la integración regional es una prioridad de la política exterior del Gobierno del Presidente colombiano Juan Manuel Santos ${ }^{23}$.

De manera general se puede plantear que el ACE No. 59, tiene como objetivo el establecer una Zona de Libre Comercio ZLC, y para ello se ha planteado un programa de liberación el cual consta de desgravaciones anuales progresivas sobre el arancel vigente para terceros países. Dichos márgenes de preferencia van creciendo progresivamente hasta llegar al 100\%. Así mismo, en torno al cronograma de desgravación se establece que este está dividido en dos ámbitos: uno general y uno especial. El general contiene productos nuevos con una desgravación que va de los 4 a los 12 años. Entorno al especial en este se incluyen el patrimonio histórico con desgravaciones de 1 a 10 años, el cronograma de sensibles con 12, 13 y 15 años; y el de liberación inmediata.

23. Colombia.com. Actualidad. Exigen revisar acuerdo comercial de Colombia con Mercosur. Obtenida el 22 de agosto de 2011 de http://www.colombia.com/ actualidad/economia/sdi/13900/exigen-revisaracuerdo-comercial-decolombia-con-Mercosur.
Lo que propone una desgravación progresiva favorable al país.

En torno a las tensiones que tiene hoy en día el proceso de integración Can-Mercosur, es sin lugar a dudas la más importante, la problemática generada por la firma de TLC entre Perú y Colombia con los EE.UU., lo cual genera una cierta incertidumbre sobre el destino de la integración Suramericana, acto por el cual Venezuela salió de la CAN en 2005 y solicitó su adhesión al Mercosur. Por ello la firma de estos bloques que ha sido anterior a la firma de los TLC de estos países, pueden generar cambios en las perspectivas regionales previstas de llegar a su consolidación, a pesar de que indirectamente se ha aceptado el activo bilateralismo comercial de Chile al ser aceptado como país asociado en dicho bloque en el 2006, condición que tenía en el Mercosur desde 1996. Así se plantea, que "no existe un pronóstico claro sobre el futuro de los compromisos originalmente firmados entre la CAN y el Mercosur y la propuesta de constitución de una alianza continental"24.

En criterio de la Cepal, los TLC suponen un retroceso en el proyecto de construcción del Mercado Común, habida cuenta de la perforación al Arancel Externo Común, la importación norteamericana puede afectar la producción local y el mercado andino con sus precios bajos. Dado que los TLC firmados no se limitan al área comercial, sino que van también sobre temas de propiedad

24. PORTA, Fernando (2008). La integración sudamericana en perspectiva. Problemas y dilemas. Comisión Económica para América Latina y el Caribe (Cepal). Buenos Aires, Argentina. Obtenida el 17 de febrero de 2011 de http://www.eclac.cl/publicaciones/ $\mathrm{xml} / 8 / 34708 /$ DocW32.pdf 
intelectual, soberanía en la solución de contenciosos judiciales, compras del estado, normas sanitarias y fitosanitarias, política de seguridad, narcotráfico y terrorismo; estos acuerdos implican la cesión de instrumentos de política considerados estratégicos. Es posible que una salida a la problemática planteada por los TLC, sea la flexibilización de la integración regional a ámbitos de una ZLC donde se sacrifican estrategias regionales por razones comerciales y políticas ${ }^{25}$. Cabe destacar que una integración regional tiene elementos de cooperación y/o mecanismos compensatorios, que en el caso del TLC con EE.UU. están totalmente ausentes ${ }^{26}$.

\section{CONCLUSIONES}

- La política de apertura comercial de la economía colombiana de las últimas décadas plantea la ampliación de mercados internacionales a ultranza, de tal manera que la integración comercial es un objetivo en sí del desarrollo del país, lo cual lo impulsa a no restringir su integración comercial a ámbitos regionales de CAN sino ampliar sus espacios a los países de la Aladi, y aun extra Aladi. Colombia propende así por un regionalismo abierto, dando cabida a convergencias regionales y tratados de libre comercio.

- El ACE 59 no es solo un tratado de libre comercio, plantea ir más allá y ser un marco jurídico e institucional

25. Ibídem.

26. FAIRLIE Reinoso, Alan (2005). Integración regional y tratados de libre comercio: algunos escenarios para los países andinos. XIX Encuentro Internacional de Ciencias Sociales. Feria Internacional del Libro. Guadalajara. Obtenida el 12 de diciembre del 2010 De http://www.contexto.org/pdfs/paper\%20libro. pdf de cooperación e integración económica y física.

- La importancia del Mercosur para Colombia reside tanto en sus ventajas estáticas como dinámicas de la integración, al proponer en primer lugar un mayor mercado a las exportaciones colombianas con valor agregado, ello dado el giro regional acontecido con la salida de Venezuela de la CAN y el reacomodo político afín de Ecuador y Bolivia con países del Mercosur. En torno al aspecto dinámico, estarían la economía de escala, integración fronteriza, inversión extranjera, y el acceso a ciencia, tecnología y aprendizaje.

- El Gobierno colombiano ha estado de acuerdo con el Acuerdo de Libre Comercio de las Américas ALCA y ha considerado que los procesos de integración regional incluyendo el ACE 59 Can-Mercosur, conducen a la integración hemisférica, sin que exista contradicción con negociaciones bilaterales con países extra Aladi. 


\section{BIBLIOGRAFÍA}

ALADI (2010). Secretaria General. Evolución del comercio negociado y aprovechamiento de las preferencias arancelarias. Estudio 199. 22 de diciembre del 2010.

ALADI (2004). Convergencia Comercial de los Países de América del Sur hacia la Comunidad Sudamericana de Naciones. Mecanismos de Defensa Comercial.

Asociación Latinoamericana de Integración Aladi (2005). Análisis descriptivo del Acuerdo de Complementación Económica $\mathrm{N}^{\circ} 59$ suscrito entre Argentina, Brasil, Paraguay y Uruguay Estados partes del Mercosur y Colombia, Ecuador y Venezuela países miembros de la Comunidad Andina. Secretaría General. SEC/di 1891. 3 de febrero de 2005.

ARELLANO, Félix G. (2004)“Comunidad Andina: de la zona de Libre Comercio a la Unión Aduanera. Los nuevos temas", en: Aldea Global, Año 8 № 16, pp. 5-15. Obtenida el 20 de octubre de 2010 de http://www.saber.ula. ve/bitstream/123456789/18166/1/articulo16-1.pdf

BALASSA, Bela (1980). Teoría de la integración. México: UTEHA S.A.

CAN (2004). Acuerdo de Complementación Económica No. 59, suscrito entre los gobiernos de la República Argentina, de la República Federativa del Brasil, de la República del Paraguay y de la República Oriental del Uruguay, Estados partes del Mercosur y los gobiernos de la República de Colombia, de la República del Ecuador y de la República Bolivariana de Venezuela, países miembros de la Comunidad Andina. Secretaría General. Documentos informativos SG/di 671, noviembre 2 de 2004. Obtenida el 20 de octubre de 2010 de http://intranet.comunidadandina.org/Documentos/D Informativos/SGdi671.pdf

CAN (2010). Acuerdo de Complementación Económica suscrito entre los Estados partes del Mercosur y los países miembros de la CAN. ACE № 59. Título VII. Aplicación y utilización de subvenciones.

DE LOMBAERDE, Philipe (2002). Integración asimétrica y convergencia económica en las Américas. Editor. Bogotá: Grupo de Investigación en Economía Internacional GREI. Universidad Nacional de Colombia, Bogotá.

Diario El País (2006). Colombia ingresa a Mercosur. Agencias y redacción. Obtenida el 25 de agosto de 2011 de: http://historico.elpais.com.co/paisonline/notas/Enero022006/a702n1.html

DURÁN, Lima José E. y ÁLVAREZ, Mariano (2008). Indicadores de comercio exterior y política comercial: mediciones de posición y dinamismo comercial. Comisión Económica para América Latina y el Caribe (Cepal). Naciones Unidas, Santiago de Chile.

FAIRLIE Reinoso, Alan (2005). Integración regional y tratados de libre comercio: algunos escenarios para los países andinos. XIX Encuentro Internacional de Ciencias Sociales (Feria Internacional del Libro. GuadalajaraNoviembre 2005). Obtenida el 12 de diciembre del 2010 de http://www.contexto.org/pdfs/paper\%20libro.pdf

GRANATO, Leonardo (2006). Aportes para la protección y defensa del inversor extranjero en el Mercosur. Obtenida el 10 de abril de 2011 de http://www.eumednet/libros/2006b/lg/index.htm

KRUGMAN, Paúl y OBSTFELD, Maurice (2006). Economía Internacional: Teoría y política. Séptima edición. Madrid: Ed. Pearson Educación S.A.

MORA Arcaya, Migdalia (2005). La incidencia en el comercio exterior venezolano de las negociaciones entre la Comunidad Andina y el Mercosur. X Jornadas de Comercio Exterior. Cámara de Industriales del Estado Carabobo. Venezuela, Valencia, 28 de julio 2004. Obtenida el 15 de abril del 2011 de www.ciec.org.ve/.../ Neg\%20CAN\%20MCS\%20-\%2028\%20Jul\%200... 
PORTA, Fernando (2008). La integración sudamericana en perspectiva. Problemas y dilemas. Comisión Económica para América Latina y el Caribe (Cepal). Buenos Aires, Argentina. Obtenida el 17 de febrero de 2011 de http://www.eclac.cl/publicaciones/xml/8/34708/DocW32.pdf

REINA, Mauricio. (2005). Escenarios de Colombia frente al ALCA. Las negociaciones comerciales de Colombia; del ALCA al TLC con los Estados Unidos. Juan Carlos Ramírez, editor. Cepal. Serie Estudios y perspectivas. Bogotá. Obtenida el 16 de agosto del 2011 de http://www.eclac.cl/colombia/noticias/documentosdetrabajo/0/20860/TLC_Col_Usa_G-ES.pdf

RODRIK, Dany (2007). “El indefectible trilema de la economía mundial”, en: Globalización.org Obtenida el 15 de junio de 2010 de http://www.globalizacion.org/globalizacion/ RodrikGlbzTrilema.htm

SIERRA, Lya Paola (2008). Impacto del acuerdo Can-Mercosur en las exportaciones del departamento del Valle del Cauca, Colombia. Perspectivas internacionales. Cali, Colombia, vol. 4 No. 1, enero-junio, 2008.

Colombia.com. Actualidad. Exigen revisar acuerdo comercial de Colombia con Mercosur. Obtenida el 22 de agosto de 2011 de http://www.colombia.com/actualidad/economia/sdi/13900/exigen-revisar-acuerdocomercial-decolombia-con-Mercosur. 